\title{
Surface Mobility and Structural Transitions of Poly(n-alkyl methacrylates) Probed by Dynamic Contact Angle Measurements
}

\author{
H. S. VAN DAMME, A. H. HOGT, AND J. FEIJEN \\ Department of Chemical Technology, Section of Biomaterials, Twente University of Technology, \\ P.O. Box 217, 7500 AE Enschede, The Netherlands
}

Received August 26, 1985; accepted January 23, 1986

\begin{abstract}
Dynamic contact angles and contact-angle hysteresis of a series of poly( $n$-alkyl methacrylates) (PAMA) were investigated using the Wilhelmy plate technique. The mobility of polymer surface chains, segments, and side groups affected the measured contact angles and their hysteresis. A model is presented in which contact-angle hysteresis of PAMA's is explained in terms of the reorientation of polymer chains and segments at the interface of the polymers with water and air. The contact angles observed also indicated structural transitions in the polymer surfaces of PAMA's that were dependent on alkyl side chain length and temperature. (c) 1986 Academic Press, Inc.
\end{abstract}

\section{INTRODUCTION}

When dynamic contact angles of polymers at the air-water interface are measured, different advancing and receding contact angles are often observed.

Contact-angle hysteresis is influenced by surface heterogeneity (1), surface roughness (2, 3 ), surface deformation (4), and chemical contamination of the water. Deformation of the polymer surface results in a very small hysteresis, even in highly deformable systems. The other influences can be minimized by employing smooth, homogeneous surfaces and hyperfiltrated water.

In addition to the above mentioned causes, contact-angle hysteresis of polymer surfaces can be induced by a change in the orientation of surface polymeric chains and their side groups or segments at the water or air interface (5-7). In particular, the mobility of hydrophilic groups on the surface of hydrogels was suggested as a factor that can influence the contact-angle hysteresis (6).

The influence of hydrophobic side chains on the surface properties of polymers has scarcely been investigated. Differences in local short range motions of short alkyl chains grafted on silica were detected using inverse gas chromatography (8), but the effect of these short range motions on contact-angle hysteresis has not been elucidated.

In a previous study we observed anomalies in the contact angle hysteresis of poly ( $n$-alkyl methacrylates) (PAMA's) (9). The aim of the present study was to investigate the cause of these anomalies by determining the effect of temperature and side chain length of a series of PAMA's on contact-angle hysteresis using the Wilhelmy plate technique.

\section{MATERIALS AND METHODS}

Polymer synthesis. The PAMA's used in this study are listed in Table I. The monomers (Polyscience, Inc., Warrington, Pa.) were purified by extraction of the inhibitor with aqueous sodium hydroxide solution (10\%). After washing with water, the monomers were distilled under reduced pressure. Polymers were synthesized by radical polymerization in toluene (solvent-to-monomer ratio 9:1 (v/v)) at $60^{\circ} \mathrm{C}$ under nitrogen for $24 \mathrm{~h}$ using $2,2^{\prime}-$ azobis(methyl isobutyrate) as an initiator (1.8 $\mathrm{mg} \mathrm{ml}^{-1}$ monomer). The initiator was synthesized from 2,2'-azoisobutyronitrile (Fluka 
TABLE I

Synthesis and Characterization of the Poly(n-alkyl methacrylates)

\begin{tabular}{|c|c|c|c|c|c|c|}
\hline \multirow[b]{2}{*}{ Polymer } & \multirow[b]{2}{*}{ Precipitant } & \multirow[b]{2}{*}{$\begin{array}{l}\text { Yield } \\
(\%)\end{array}$} & \multicolumn{3}{|c|}{ Molecular weights } & \multirow[b]{2}{*}{$\begin{array}{c}T_{\mathrm{B}} \\
\left({ }^{\circ} \mathrm{C}\right)\end{array}$} \\
\hline & & & $\bar{M}_{\mathrm{a}} \times 10^{-4}$ & $\bar{M}_{w} \times 10^{-4}$ & $\bar{M}_{\mathrm{w}} / \bar{M}_{\mathbf{m}}$ & \\
\hline Poly(methyl methacrylate) & Pet $60 / 80^{b}$ & 42 & 8.9 & 14.0 & 1.58 & $120(105)^{a}$ \\
\hline Poly(n-butyl methacrylate) & Methanol & 47 & 12.2 & 19.0 & 1.55 & $20(20)$ \\
\hline Poly(n-pentyl methacrylate) & Methanol & 11 & 9.3 & 14.4 & 1.56 & - \\
\hline Poly(n-hexyl methacrylate) & Methanol & 35 & 12.1 & 20.4 & 1.68 & $4(-5)$ \\
\hline $\operatorname{Poly}(n$-heptyl methacrylate) & Methanol & 56 & 12.4 & 20.0 & 1.62 & -2 \\
\hline Poly(n-octyl methacrylate) & Methanol & 24 & 13,8 & 22.1 & 1.60 & $(-20,-70)$ \\
\hline Poly(n-nonyl methacrylate) & Ethanol & 47 & 12.5 & 22.6 & 1.80 & -24 \\
\hline Poly(n-decyl methacrylate) & Ethanol & 32 & 12.0 & 19.6 & 1.63 & $(-70)$ \\
\hline Poly ( $n$-dodecyl methacrylate) & Ethanol & 12 & 11.7 & 22.3 & 1.91 & $(-65)$ \\
\hline Poly(n-octadecyl methacrylate) & Ethanol & 28 & 9.7 & 17.3 & 1.78 & $(-100)$ \\
\hline
\end{tabular}

${ }^{a}$ Values obtained from the literature (10) are given in parentheses.

${ }^{b}$ Petroleum ether, boiling point $60-80^{\circ} \mathrm{C}$.

AG, Buchs, Switzerland) as described by Mortimer (11). Polymers were precipitated twice in nonsolvent and dried under reduced pressure.

Molecular weights. Molecular weights were determined using a High-Pressure Liquid Chromatography-Low Angle Laser Light Scattering system (HPLC-LALLS). The LALLS used was a Chromatix Model KMX6 (Milton Roy, Division LDC, Stone, U.K.). A Waters, Model R 401 (Milford, Mass.) differential refractometer was used to measure concentrations at $\lambda=633 \mathrm{~nm}$. PAMA's with $n=1-10$ ( $n$ is the number of $\mathrm{C}$ atoms in the alkyl side chain) were dissolved in butanone, and the solutions were applied to SE 1000, SE 500 , and SE 100 columns (DuPont de Nemours, Wilmington, Del.) which were used in series. The flow rate was $2.02 \mathrm{ml} \mathrm{m^{-1 }}$. PAMA's with $n=12$ and $n=18$ were dissolved in tetrahydrofuran. $\mu$-Styragel HPLCcolumns with exclusion limits of $10^{5}, 10^{4}, 10^{3}$, and $500 \AA$ were used in series for these polymers, employing a flow rate of $1.04 \mathrm{ml} \mathrm{min}^{-1}$.

Glass transition temperatures. Glass transition temperatures $\left(T_{\mathrm{g}}\right)$ of PAMA's were determined using differential scanning calorimetry (DSC-2, Perkin-Elmer, Norwalk, Conn.). Transitions were measured several times at a heating rate of $10^{\circ} \mathrm{C} \mathrm{min}-1$ and a range setting of $1 \mathrm{mcal} \mathrm{s}^{-1}$ full scale. Prior to measurement, the samples were maintained at a temperature well below $T_{\mathrm{g}}$ for at least $10 \mathrm{~min}$.

Preparation of thin polymer coatings. Polymer solutions in toluene $(3 \%)$ were filtered through $0.45-\mu \mathrm{m}$ membrane filters (Type FP 030/70, Schleicher \& Schull, GmbH, Dassel, F.R.G.) and stored in particulate-free brown bottles. Polymer coatings were prepared by slow $\left(4 \mathrm{~cm} \mathrm{~min}^{-1}\right)$, uniform dipping of cleaned silane-treated microscope glass coverslips (Type No. 1, $25 \times 50 \mathrm{~mm}$, Propper, Ltd., Smethwich, Warley, U.K.). The films were dried for $3 \mathrm{~h}$ at $60^{\circ} \mathrm{C}$ in a nitrogen atmosphere. Polymer coatings on silanized glass were examined with a light microscope and were smooth, homogeneous, and particle-free.

Coverslips were cleaned by immersion in chromic acid for $20 \mathrm{~min}$ at $80^{\circ} \mathrm{C}$. The coverslips were then rinsed four times for $1 \mathrm{~min}$ with hyperfiltrated water to remove residual chromic acid, and two times for 3 min with ethanol to remove excess water. The coverslips were transferred to a chlorotrifluoroethylene (Freon TF, DuPont de Nemours) vapor bath for $10 \mathrm{~min}$. The cleanliness of the glass was assessed by Wilhelmy plate contact-angle measurements. Coverslips were always cleaned 
immediately prior to silanization. Silanization was performed with aminopropyltriethoxysilane (Janssen Chemica, Beerse, Belgium) as described by Haller (12).

Dynamic contact-angle measurements. Dynamic contact angles were measured using the Wilhelmy plate technique $(13,14)$. The polymer-coated coverslips were immersed in a beaker containing hyperfiltrated water at a speed of $11 \mathrm{~mm} \mathrm{~min}{ }^{-1}$. The temperature of the water was varied between 5 and $50^{\circ} \mathrm{C}$, and the room temperature was maintained at $20^{\circ} \mathrm{C}$. The surface tension of hyperfiltrated water $\left(\gamma_{1 v}\right)$ at $20^{\circ} \mathrm{C}$ was determined to be 72.6 $\times 10^{-3} \pm 0.5 \times 10^{-3} \mathrm{~N} \mathrm{~m}^{-1}$ using completely wetting, ultraclean coverslips. To obtain the wetting curves, the weight of the coverslips was measured as a function of the immersion depth with an electrobalance (Model RM-2, Chan/Ventron, Paramount, Calif.). After extrapolation of the plots obtained for the advancing and receding modes to zero immersion depth, contact angles $(\theta)$ were calculated from

$$
\left(m-m_{0}\right) g=p \gamma_{\mathrm{lv}} \cos \theta+V \rho g,
$$

in which $m g(\mathrm{~N})$ represents the weight of the slide as measured with the electrobalance, $m_{0} g$ the weight of the sample immediately after retraction from the water bath, $g$ the local gravitational constant $\left(9.812 \mathrm{~m} \mathrm{~s}^{-2}\right), p$ the perimeter of the sample $(p=0.0484 \mathrm{~m}$ for coverslips), $V\left(\mathrm{~m}^{3}\right)$ the volume of immersed sample at particular depth, and $\rho\left(\mathrm{kg} \mathrm{m}^{3}\right)$ the density of the liquid. The buoyancy factor $V \rho g$ could be eliminated after extrapolation to zero depth.

\section{RESULTS}

\section{Synthesis of Polymers and Characterization}

The results of the polymer synthesis and polymer characterization are presented in Table I. PAMA's with $n=1,4,5,6,7,8,9,10$, 12 , and 18 were synthesized. Yields varied from 12 to $56 \%$. Number average molecular weights $\left(\bar{M}_{\mathrm{n}}\right)$ varied from $8.9 \times 10^{5}$ to 13.7 $\times 10^{5}$. Weight average molecular weights $\left(\bar{M}_{\mathrm{w}}\right)$ varied from $14.1 \times 10^{5}$ to $22.6 \times 10^{5}$. All $\bar{M}_{\mathrm{w}} /$
$\bar{M}_{\mathrm{n}}$ ratios obtained were between 1.5 and 2.0 (Table I).

The glass transition temperatures determined for the polymers were close to values reported in the literature (10).

\section{Dynamic Contact Angles}

Dynamic advancing and receding water contact angles were determined on PAMA's at various temperatures. At $20^{\circ} \mathrm{C}$, advancing contact angles were observed to increase from 95 to 116 degrees with increasing alkyl side chain length (Fig. 1). Receding contact angles reached a maximum of 75 degrees on PAMA $(n=6)$ and a minimum of 40 degrees on PAMA $(n=12)$. From the nine polymer coatings of each PAMA used for contact angle determination at $20^{\circ} \mathrm{C}$, three were selected for contact-angle measurements at other temperatures.

When the temperature was raised to $50^{\circ} \mathrm{C}$, the lowest receding contact angle (36 degrees) was observed for PAMA $(n=10)$ (Fig. 2).

At a temperature of $5^{\circ} \mathrm{C}$, contact angles of all polymers remained similar to those measured at $20^{\circ} \mathrm{C}$, except for the receding angle of PAMA $(n=18)$. This angle increased

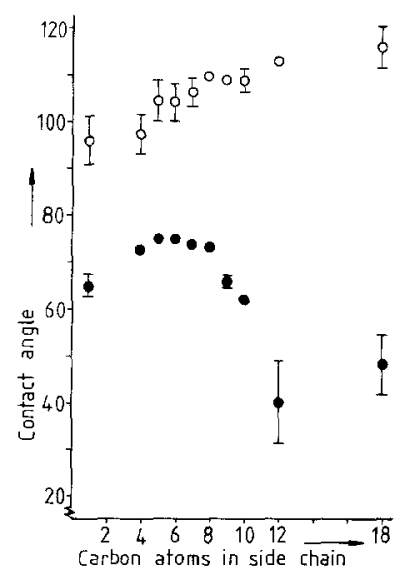

FIG. 1. Dynamic contact angles of poly $(n$-alkyl methacrylates) at $20^{\circ} \mathrm{C}$. (O) Advancing contact angle, (0) receding contact angle. Bars indicate standard deviation. Each point represents the results obtained from nine coverslips. 


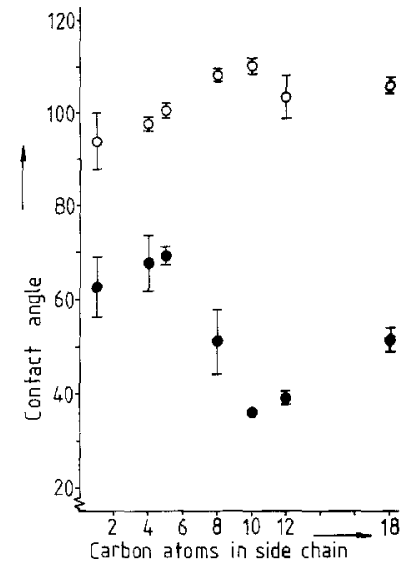

FIG. 2. Dynamic contact angles of poly( $n$-alkyl methacrylates) at $50^{\circ} \mathrm{C}$. (O) Advancing contact angle, (๑) receding contact angle. Bars indicate standard deviation. Each point represents the results obtained from three coverslips.

sharply from 48 degrees at $20^{\circ} \mathrm{C}$ to 80 degrees at $5^{\circ} \mathrm{C}$.

After storing the PAMA $(n=18)$ samples in air for 3 weeks their contact angles were measured in the temperature range of 5 to $20^{\circ} \mathrm{C}$ (Fig. 3). For the first measurement, taken at $20^{\circ} \mathrm{C}$ (point 1 ) the advancing contact angle was 111 degrees. The angle decreased to 103 degrees in the second measurement taken at $15^{\circ} \mathrm{C}$ (point 2) and remained constant in the subsequent measurements (points 3, 4, and 5) taken at 10,5 , and $18^{\circ} \mathrm{C}$, respectively.

\section{DISCUSSION}

As expected PAMA's with increasing alkyl side chain length exhibit more hydrophobic surfaces which results in increasing advancing contact angles (Fig. 1). The increasing receding contact angles measured for PAMA $(n=1-$ 6) may similarly be attributed to the increased hydrophobicity induced by the alkyl side chains. The contact-angle hysteresis of these rigid polymers can be explained by polymer side chain beta-relaxations (3).

The decrease of the receding contact angles observed when the length of the alkyl side chains exceeds $n=6$ was unexpected and may be explained by an increased mobility of large polymeric segments at the PAMA surface. This increase in mobility of surface groups may be correlated with a change in the mobility of the bulk polymer segments which is exhibited as a decrease in $T_{\mathrm{g}}$ (Table I). This effect is due to internal plasticization of the PAMA's by the alkyl side groups (16). Increased mobility might result in reorientation of ester groups at the surface in the water phase, causing a lower receding contact angle as compared with the advancing angle (6). For the PAMA's with $n>6$ however it is unlikely that a reorientation of ester groups at the surface is the greatest contributory factor to the observed increase in contact-angle hysteresis. It is most likely that as the alkyl side chain length increases the ester groups are more shielded, and their relative contribution to contact-angle hysteresis is effectively diminished.

Flexible hydrophobic side chains of PAMA surfaces may reorient when exposed to water. When this reorientation is slow in relation to the movement of the interface, but fast relative to the residence time in water between the advancing and receding movement, the receding

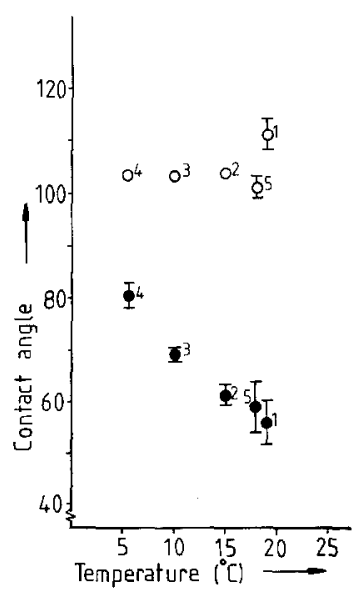

FIG. 3. Dynamic contact angles of PAMA $(n=18)$ at different temperatures. (O) Advancing contact angle, (e) receding contact angle. Bars indicate standard deviation. Numbers indicate wetting sequence. Each point represents results obtained from the same three coverslips. The intervals between measurements were $30 \mathrm{~min}$. 
angle will be lowered as compared with the advancing angle. In formula (15),

$$
V=l / \tau
$$

a relation is given between the displacement speed $(V)$ of the water-air interface, the thickness of the three-phase junction across the solid phase $(l)$ and the residence time $(\tau)$ of molecular groups at the surface in the threephase junction. With a displacement speed $(\mathrm{V})$ of $0.02 \mathrm{~cm} \mathrm{~s}^{-1}$ used in our experiments and a three-phase junction thickness $(l)$ of $10^{-6} \mathrm{~cm}$, this residence time will be $5 \times 10^{-7} \mathrm{~s}$. When molecular groups at the surface can reorient with a relaxation time longer than $\tau$ but shorter than the residence time in the water phase, which is in the order of minutes, reorientation of these groups will take place after they pass the three-phase junction in the advancing movement, but before they pass this junction again in the receding movement. In this time range, from $5 \times 10^{-7}$ s to several minutes, several $\alpha$ and $\beta$ relaxations of PAMA's can be expected to take place (17).

The decrease in receding contact angles of PAMA's with $n>6$ may thus be explained by using a model as presented in Fig. 4. In the original situation (a), the hydrophobic alkyl chains may be preferentially oriented toward the vapor phase. This situation will not change

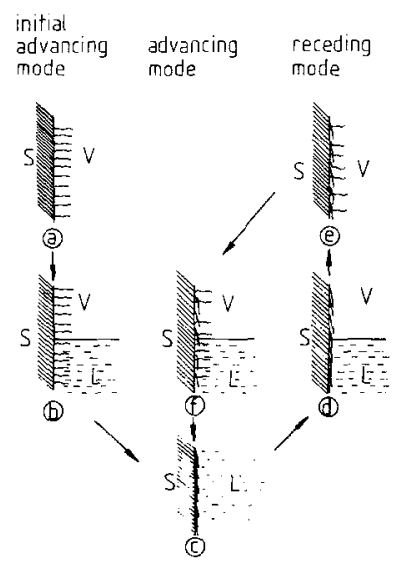

FIG. 4. Model for reorientation of surface molecules after wetting to explain contact-angle results. S, solid; V, vapor; L, liquid. during the measurement of the initial advancing contact angle (b). During the residence in the water phase (c) between the measurement of the advancing and the receding contact angle, the surface molecules may reorganize by an increased interaction between the alkyl side chains at the surface. This increased interaction will lead to a decreased number of hydrophobic segments which interact with water, resulting in a decrease of the interfacial free energy and consequently of the interfacial tension $\left(\gamma_{\mathrm{sl}}\right)$. The receding contact angle is measured on the reoriented surface (d), which has a higher interfacial tension with the vapor phase $\left(\gamma_{\mathrm{sv}}\right)$ than the original surface. The higher interfacial energy is caused by a decrease of the entropy which is due to the increased interaction of the alkyl side chains. According to Young's law:

$$
\gamma_{\mathrm{lv}} \cos \theta=\gamma_{\mathrm{sv}}-\gamma_{\mathrm{sl}} \text {. }
$$

The increased $\gamma_{\mathrm{sv}}$ and the decreased $\gamma_{\mathrm{sl}}$, then result in a receding contact angle which will be lower than the advancing contact angle. When returned to air (e), the surface molecules will tend to reorganize to their original conformation. In subsequent contact-angle measurement cycles, decreased advancing contact angles were observed (Fig. 3), indicating that the return of surface molecules to their original conformation is not complete. A number of subsequent contact-angle measurements performed over equally short time intervals gave constant advancing contact angles, according to situation (f) in the model.

Decreased receding contact angles are observed for PAMA $(n=8$ or $n=10)$ at $50^{\circ} \mathrm{C}$. Apparently the mobility of surface polymer chains or segments of these polymers increases significantly between 20 and $50^{\circ} \mathrm{C}$ enabling the surface to reorganize in water. When the temperature is lowered from 20 to $5^{\circ} \mathrm{C}$, PAMA $(n=18)$ shows an increase in receding contact angle, probably due to decreased mobility of polymeric segments. The interaction between the long side chains of this polymer probably inhibits surface reorganization in water.

Phase transitions in monolayers of PAMA's 
at water-air interfaces were observed by Crisp (18). At room temperature a PAMA $(n=1)$ monolayer exhibited solid behavior, while a PAMA $(n=4)$ monolayer displayed several phase transitions and liquid behavior. When a PAMA $(n=18)$ monolayer was compressed and the temperature was raised from 20 to $30^{\circ} \mathrm{C}$, liquefaction of the solid layer was observed. Crisp suggested that the alkyl side chains of PAMA $(n=18)$ largely determined the state of the monolayer. It is realized that monolayers behave differently from the surfaces of the thin films investigated here by contact-angle measurements; nevertheless, the behavior of the PAMA surfaces is analogous to the behavior of monolayers reported by Crisp, although the transitions occur at different temperatures.

\section{CONCLUSIONS}

Water contact-angle hysteresis of PAMA's as measured by the Wilhelmy plate technique may be explained by the reorganization of polymer side chains or segments at the polymer surface.

When the side chain length of PAMA's is increased from $n=6$ to $n=12$ the mobility of polymeric segments increases due to internal plasticization. This allows a reorganization of polymer segments at the interface when in contact with water. Further increase in the length of the side chain $(n=18)$ reduces the mobility of polymer segments and impedes the reorientation of polymeric groups at the interface.

Changes in contact-angle hysteresis measured at different temperatures suggest structural transitions in the polymeric surface involving changes in mobility of polymeric chains or segments.

\section{ACKNOWLEDGMENTS}

We wish to thank G. van de Ridder for determining the molecular weights of the polymers and L. Dost for his involvement to use the Wilhelmy plate apparatus. We also express our gratitude to Dr. Andrade for his helpful discussions.

\section{REFERENCES}

1. Neumann, A. W., and Good, R. J., J. Colloid Interface Sci. 38, 341 (1972).

2. Eick, J. D., Good, R. J., and Neumann, A. W., J. Colloid Interface Sci. 53, 235 (1975).

3. Andrade, J. D., Gregonis, D. E., and Smith, L. M., "Physicochemical Aspects of Polymer Surfaces," Vol. 2, p. 911. Plenum, New York/London, 1982.

4. Andrade, J. D., King, R. N., Gregonis, D. E., and Coleman, D. L., J. Polym. Sci., Polym. Symp. 66, 313 (1979).

5. Holly, F. J., and Refojo, M. F., J. Biomed. Mater. Res. 9, 315 (1975).

6. Yasuda, H., and Sharma, A. K., J. Polym. Sci., Polym. Phys. Ed. 19, 1285 (1981).

7. Ruckenstein, E., and Gourisankar, S. V., J. Colloid Interface Sci. 107, 488 (1985).

8. Kessaissia, Z., Papirer, E., and Donnet, J. B., J. Colloid Interface Sci. 79, 257 (1981).

9. Hogt, A. H., Gregonis, D. E., Andrade, J. D., Kim, S. W., Dankert, J., and Feijen, J., J. Colloid Interface Sci. 106, 289 (1985).

10. Brandrup, J., and Immergut, E. H., Eds., "Polymer Handbook," 2nd ed. Wiley, New York, 1975.

11. Mortimer, G. A., J. Org. Chem. 30, 1632 (1965).

12. Haller, I., J. Amer. Chem. Soc. 100, 8050 (1978).

13. Adamson, A. W., "Physical Chemistry of Surfaces," p. 26. Wiley, New York, 1967.

14. Smith, L., Doyle, D. E., Gregonis, D. E., and Andrade, J. D., J. Appl. Polym. Sci. 27, 1269 (1982).

15. Hansen, R. S., and Miotto, M., J. Amer. Chem. Soc. 79, 1765 (1957).

16. McCrum, N. G., Read, B. E., and Williams, G., "Anelastic and Dielectric Effects in Polymeric Solids,” p. 238. Wiley, New York, 1967.

17. Child, W. C., Jr., and Ferry, J. D., J. Colloid Interface Sci. 12, 389 (1957).

18. Crisp, D. J., J. Colloid Interface Sci. 1, 161 (1946). 